\title{
Distribution of neodymium isotopes along the GEOTRACES Eastern Pacific Zonal Transect
}

\author{
YINGZHE $\mathrm{WU}^{1 *}$, CHANDRANATH BASAK ${ }^{1,2}$, JESSE M.
} MURATLI $^{3}$, STEVEN L. GoldSTEIN ${ }^{1}$, Brian A. HALEY ${ }^{3}$, LEOPOLDO D. PENA ${ }^{4}$, LOUISE L. BOLGE ${ }^{1}$

${ }^{1}$ Lamont-Doherty Earth Observatory of Columbia University, Palisades, New York 10964, USA (*correspondence: yingzhe@1deo.columbia.edu)

${ }^{2}$ Department of Earth Sciences, University of Delaware, Newark, DE 19716, USA

${ }^{3}$ Oregon State University, Corvallis, OR, USA

${ }^{4}$ GRC Geociències Marines, Department of Earth and Ocean Dynamics, University of Barcelona, Barcelona 08028, Spain

The GEOTRACES Eastern Pacific Zonal Transect (EPZT, GP16) from Peru to Tahiti provides a great opportunity to understand sources, sinks and cycling of neodymium $(\mathrm{Nd})$ in the ocean as well as how well $\mathrm{Nd}$ isotopes behave as a conservative water mass tracer because the EPZT crosses different environments, including a continental margin, an oxygen minimum zone, an oceanic ridge, and open ocean. We report the distribution of dissolved $\mathrm{Nd}$ isotopes from 21 stations in the EPZT. Most of the surface samples, from 0 to $\sim 10 \mathrm{~m}$, show $\varepsilon N d$-values between -2 and 1 , reflecting terrigeneous contributions from South America. $\varepsilon N d$-values of shallow samples, from $\sim 10$ to $\sim 500 \mathrm{~m}$, range between -4 and -1 , consistent with $\varepsilon N d$-values of Equatorial Subsurface Water, Eastern South Pacific Intermediate Water, and South Pacific Central Water. Above and west of the East Pacific Rise (EPR), below $\sim 500 \mathrm{~m}, \varepsilon N d$-values gradually decrease with depth, reflecting contributions from Antarctic Intermediate Water $(\varepsilon \mathrm{Nd}=-7)$, Circumpolar Deep Water $(\varepsilon \mathrm{Nd}=-8)$, and Antarctic Bottom Water $(\varepsilon \mathrm{Nd}=-8)$. However, from $\sim 2300$ to $2800 \mathrm{~m}$, the EPR and western stations show an increase of $\varepsilon \mathrm{Nd}$, as high as $1 \varepsilon \mathrm{Nd}$-unit at the EPR. This indicates that hydrothermal $\mathrm{Nd}$ can modify seawater $\varepsilon N d$ near the EPR. East of the EPR, seawater shows higher $\varepsilon N d$-values compared to west of the EPR, especially for stations from $84^{\circ} \mathrm{W}$ to the Peruvian margin between $\sim 500$ and $2000 \mathrm{~m}$ water depth. The higher $\varepsilon \mathrm{Nd}$-values close to the Peruvian margin could be attributed to $\mathrm{Nd}$ contributions from marginal sediments. Below $2000 \mathrm{~m}$, $\varepsilon N d$-values on the eastern side of the EPR range between -4 and -3 , indicating dominance of Pacific Deep Water $(\varepsilon N d=-4)$. These results indicate that $\mathrm{Nd}$ isotopes in the open ocean largely behaves as a conservative water mass tracer, while deviations from conservative behavior are observed close to continental margins and from hydrothermal input. 